\title{
Dyspepsia: when to endoscope?
}

\begin{abstract}
Introduction: Dyspepsia refers to a set of gastro duodenal symptoms, four of which are major: postprandial fullness, early satiety, epigastric pain and burning. There are disadvantages in the requests for immediate endoscopies for all patients with dyspeptic symptoms. The high prevalence of dyspepsia in the population means that the request for endoscopy for all would reflect a high cost and would burden the services. The indiscriminate application of endoscopies does not promote benefit.
\end{abstract}

Objective: To know if the endoscopy was well addressed in our Endoscopy Center_Santo André knowing the correlation between dyspeptic syndrome and endoscopic findings.

Methods: Cross-sectional study was conducted at the Digestive Endoscopy Service of the ABC Medical School. In the waiting room of endoscopy service 102 patients already addressed to endoscopy exam, agreed to fulfill a questionnaire in which demographic data and symptoms with their main characteristics were collected. The researchers did not indicate the exam requests. Consecutive, selected participants aged 15 to 60 years who are diagnosed with dyspepsia and were indicated to perform upper digestive endoscopy were included and the endoscopy findings were computed.

Results: The main complaint was heartburn (31.3\%), related to food (56\%). Among the alarm signals, the most observed was weight loss (35\%), duration of symptoms greater than 6 months $(72.5 \%)$, high frequency during the week $(38 \%) .59 \%$ of patients were taking proton pump inhibitor - Omeprazole and we verified that $60 \%$ of patients had no need for endoscopy and $84.8 \%$ had functional dyspepsia. Among the patients who tested for Helicobacter pylori, $38.15 \%$ had a positive result.

Discussion: Most of the indications were not judicious, which implies considerable damage to the public coffers, especially in a country with scarce resources like Brazil.

Conclusion: In our region, there are indiscriminate indications of endoscopies, which cause unnecessary expenses, requiring the approval of a new guideline for developing countries, in order to optimize spending and waiting line.

Keywords: dyspepsia, endoscopy, signs and symptoms, gastroenterology
Volume II Issue 6 - 2020

\section{Thainá Altarejo Marin,' Maria Laura Jorge Micheletto,' Paulo R Giovannetti Massabki,' Maria Isabel Cardoso,' Amanda Ribeiro Batlle,' Ana Paula Possar do Carmo,' Ethel Zimberg Chehter ${ }^{2}$ \\ 'Researcher, ABC Medical School, Brazil \\ ${ }^{2}$ Department of Gastroentherology, Faculdade de Medicina do} ABC, Brazil

Correspondence: Ethel Zimberg Chehter, Faculdade de Medicina do ABC, Av. Lauro Gomes, 2000 Anexo II sala I8.Vila Sacadura Cabral- Santo André, Brazil,

Email Chehter.ops@terra.com.br

Received: October 13, 2020 | Published: November 25, 2020
Abbreviations: GERD, gastroesophageal reflux disease; PDS, Post distress syndrome; EPS, epigastric pain syndrome; UDE, upper digestive endoscopy

\section{Introduction}

When researching the concept of dyspepsia in gastroenterology books and in databases (SciELO, LILACS, PubMed), it is possible to note that this definition is still very controversial. This is justified, since several authors diverge when presenting the meaning of dyspepsia: some consider it to be only pain or discomfort located in the central and upper abdomen, while others add to the concept the presence of heartburn, regurgitation, heartburn.

Our most difficulty is a good guideline for uninvestigated dyspepsia. So it is important to know differential diagnosis between organic and functional dyspepsia and when to indicated endoscopy.

The non-investigated dyspepsia can result in two possible end pointing: functional dyspepsia or organic dyspepsia. Organic dyspepsia is defined when clinical and laboratory characteristics identify an organic disease that is likely to be causing the symptoms. The main causes of organic dyspepsia are: peptic ulcer, gastroesophageal reflux disease (GERD), gastric or esophageal cancer, pancreatic or biliary tract disorders, intolerance to drugs and food, among other. On the other hand functional dyspepsia: Rome III Consensus is taken as the basis for this work, which defines dyspepsia as a set of symptoms that normally arise from the gastroduodenal region, maintaining only 4 cardinal symptoms, namely: Post distress syndrome (PDS: postprandial fullness, early satiety, or epigastric pain syndrome (EPS: epigastric pain and epigastric burn., in which the symptoms must be met in the last 3 months with the onset of symptoms at least 6 months before the diagnosis AND with no associated organic diseases (including endoscopy). And in 2016, the Rome IV Consensus was proposed with the same criteria used..$^{1-21}$

What about the incidence of dyspepsia? The incidence of dyspeptic syndrome is around $40 \%$ of the general population and $25 \%$ of patients characterized this condition as the main complaint in consultations. ${ }^{21,22}$ In the United States, a study demonstrated that functional dyspepsia was the most frequent cause of this condition, with a prevalence of $31.9 \%$. However, when GERD cases are excluded by the Rome II and III criteria, the prevalence reduces to $15.8 \%{ }^{21,23}$ In Brazil it may vary from $44 \%$ to $68,6 \% .^{24}$

When addressed endoscopy? According to the American College of Gastroenterology guidelines, dyspeptic patients over 55 or with alarm factors: bleeding, anemia, unexplained weight loss (more than $10 \%$ of body mass), progressive dysphagia, odynophagia, persistent vomiting, family history gastrointestinal cancer, previous history of esophageal malignancy, peptic ulcer, lymphadenopathy or abdominal mass, should be promptly referred for upper gastrointestinal endoscopy to rule out the possibility of peptic ulcer disease, neoplasms and other rare gastrointestinal diseases. ${ }^{25}$ On the other hand, in patients aged 55 years or younger, without alarm factors, other options should be 
considered. The test and treat method is preferable in populations with moderate to high prevalence of H.pylori infection. ${ }^{25,26}$ However, endoscopy is not recommended once a diagnosis of functional dyspepsia is confirmed, unless new symptoms have arisen, or alarm symptoms. Repeated endoscopies are also not recommended as they are not cost effective. ${ }^{25}$

Other approaches for addressed endoscopy: 1. In a study by Salihefendic N1, Zildzic M2, Cabric E3, it is observed that clinical guidelines recommended the upper gastrointestinal endoscopy and the Helicobacter pylori (HP) test as the gold standard in the diagnostic evaluation. They also requested an abdominal ultrasound as a diagnostic procedure that is not aggressive, is easy to perform, inexpensive and becomes very popular in practical family medicine, but there are few studies to assess the diagnostic value in the USA. ${ }^{27}$ 2. Sanchez et al. ${ }^{17}$ recommended endoscopy on all patients with dyspepsia not investigated with symptoms and warning signs or when initial treatment failure guided by the predominant symptom. ${ }^{17} 3$. In our country (Brazil), a study conducted by the University of São Paulo - São Paulo group in 2008 also concluded that the use of endoscopy to screen for dyspeptic syndrome in all patients with complaints in the office is considered unnecessary and the approach in these patients must follow an order to avoid excessive examination with complaints that can be controlled clinically.

Several approaches were developed in order to reduce the need for endoscopy for definitive treatment of dyspepsia, one of which started with the investigation of alarm signals to guide the examination request. Signs include: unexplained weight loss, anemia, digestive bleeding, progressive dysphagia, persistent vomiting, previous gastric surgery, visceromegaly, jaundice, abdominal tumor or adenopathy, systemic symptoms and age over 55years. Figure 1 helps the comprehension about when we can indicate endoscopy.

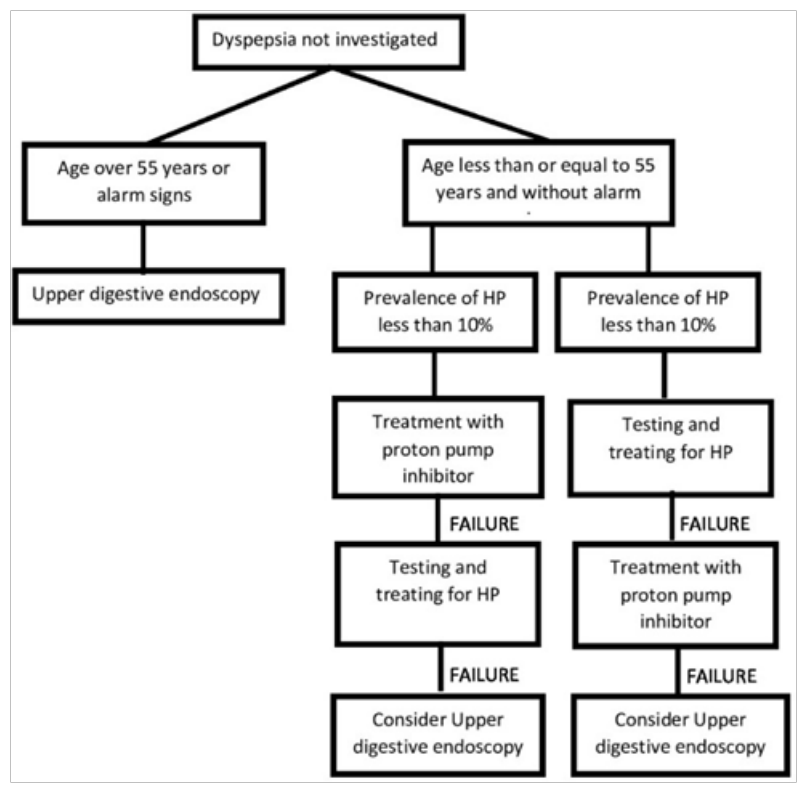

Figure I Management of dyspepsia not investigated (adapted from the article "Guidelines for the Management of Dyspepsia" de Talley NJ,Vakil N e Practice Parameters Committee of the American College of Gastroenterology (2005). American Journal of Gastroenterology. ${ }^{18}$

In order to assess the excessive request for upper gastrointestinal endoscopy in a well-developed city, in 2016, our group Gastroenterology Faculdade de Medicina ABC, published a paper named "Dyspepsia and Endoscopy: For whom and when?-Profile of Endoscopic Findings in 750 Patients". The main objective was to profile endoscopic findings in exams performed at the Endoscopy Center of ABC Medical School. For this, 750 results of endoscopy procedures performed at the institution were reviewed. The exams analyzed included individuals with a mean age of $44,55 \pm 11.65$ (mean \pm standard deviation), ranging from 15 to 72 years, with 230 men and 520 women. The study showed that 135 endoscopies were normal (18\%) and 412 had findings that did not coincide with the clinical manifestations, totaling 547 (72.8\%) of endoscopies without clinical diagnostic importance. The result of this study corroborates the burden of the Brazilian health system with the demand for high digestive endoscopies without an adequate indication and real need. ${ }^{29}$

Given the importance of the subject, did a prospective study of analysis of endoscopic reports, verifying the patient's clinical condition and if the requests for endoscopic exams are carried out correctly. Our main objective was not to treat or diagnosis. The study allows verifying when we can indicate endoscopy according to symptoms.

\section{Objective}

In our Endoscopy Center ABC region - São Paulo Brazil: To know if the dyspeptic symptoms had correlation with the endoscopic findings. Is the endoscopy well addressed?

\section{Material and methods}

This prospective study was conducted at the Digestive Endoscopy Service of the Faculdade de Medicina $\mathrm{ABCl}$ in Santo André - SP in 2019. The Faculty is located at Avenida Lauro Gomes, 2000 and the endoscopy service takes place in the central building of The Faculty.

In the Endoscopy waiting room, we invite patients, already addressed for endoscopy by outside doctors, to participate of our study. They answer a questionary of dyspeptic syndrome and agree to share the endoscopy results, by fulfilling an informed consent approved by the Ethic Committee of Faculdade de Medicina ABC number 2.675061 .

Participants received the Consent Form, which explains the risks and benefits of participating in the study. The risks are considered minimal, and are related to secrecy and confidentiality. As it is an observational study, the risks can be in discomfort when answering the questionnaire and, by answering the questionnaire before the exam, the fasting time will increase by approximately 5 minutes. The benefits of participating will be that, in addition to contributing to scientific research, participants will never be identified will not receive any payment for their participation, but will also have no expense. The related institution (Faculdade de Medicina do $\mathrm{ABC}$ ) will also have no expenses. The participant may also at any time in the study withdraw from participating and withdraw his consent, also without any loss or damage.

So, the included patients answered the questionnaire, where demographic data such as age, sex, marital status, color and habits (alcohol and smoking) will be collected, in addition to the symptoms with their main characteristics.

After answering the questionnaire, everyone will be submitted to upper digestive endoscopy with Pentax videoendoscope, after a minimum of 6hours of fasting and under intravenous sedation. Examining physicians will not have access to the result of the questionnaire. 
In our study dyspepsia was characterized by complaints of epigastric pain, postprandial packing, indigestion, heartburn, nausea or regurgitation (Roma III). Although the Rome IV criteria were updated, the Rome III criteria were used to apply the questionnaire, for sample convenience. The aim is to analyze which patients had any of these symptoms when they were indicated to do an endoscopy.

Endoscopic findings characteristic of organic disease will be considered: erosive esophagitis, Barrett's esophagus, esophageal stricture, Schatski ring, esophageal carcinoma, esophageal candidiasis, gastric ulcer, gastric carcinoma and duodenal ulcer. Gastritis or duodenitis diagnosed by enanthema of the mucosa or by histopathological diagnosis, will not be considered as organic disease. Biopsies will be performed at the endoscopist's discretion and histological findings such as eosinophilic esophagitis, Crohn's disease, celiac disease and villous atrophy will also be considered as organic disease. ${ }^{11}$ The search for Helicobacter pylori by the use of urease test or histopathological method will be performed is the patient fulfil the Rome III criteria.

We included 102 participants aged between 15 and 60years, who have a previous diagnosis of dyspepsia and have been addressed to upper endoscopy, will be included. Exclusion criteria for the study are participants who have any comorbidities which prevents to do the endoscopy, $<15$ or $>60$ years old and/or refuse to answer the questionnaire.

Statistics: Qualitative variables were presented by absolute frequency and relative frequency. The Chi- square test was used to analyze the association between the complaint and the age group with the results of the endoscopy. The confidence level adopted was $95 \%$. The statistical program used was Stata version 11.0.

\section{Results}

102 patients were interviewed. From the analysis of the questionnaire responses, it is demographic analysis that approximately $72 \%$ of the patients analyzed are female, determining that 73 women and 29 men were interviewed. The average age was 45.54 years. The profession most cited among patients was: home and self- employed (both with $28.4 \%$ ) (Table 1).

Table I Prevalence of patients according to gender

\begin{tabular}{lll}
\hline & Percentage & Absolute value \\
\hline Feminine & $71,6 \%$ & 73 \\
Male & $28,4 \%$ & 29
\end{tabular}

Heartburn was the most frequent complaint, followed by epigastric pain and nausea. Abdominal distension, epigastric burning, bundling and eructations were rarely observed. Most complaints were linked to food (about $60 \%$ ), and the majority did not report links to bowel habits(Table 2).

Table 2 Prevalence of patients according to complaints

\begin{tabular}{lll}
\hline Complaints & Percentage & Absolute value \\
\hline Heartburn & $31,3 \%$ & 41 \\
Nausea & $13 \%$ & 22 \\
Epigastric pain & $26,7 \%$ & 63 \\
Abdominal distension & $4,6 \%$ & 10 \\
\hline
\end{tabular}

Table continue

\begin{tabular}{lll}
\hline Complaints & Percentage & Absolute value \\
\hline Gastric burning & $8,4 \%$ & 28 \\
Bundling & $3,1 \%$ & 13 \\
Eructations & $2,3 \%$ & 5 \\
Others & $6,9 \%$ & 9 \\
\hline
\end{tabular}

As for the characteristics of the complaints, we obtained the following results: The vast majority were of epigastric location (more than $75 \%$ ); burning type; medium intensity, with the majority giving a ' 5 ' score to the pain, followed by a ' 10 ' score; without irradiation; with a high frequency, 4 times or more during the week (Table 3).

Table 3 Prevalence of patients according to pain location and its characteristics

\begin{tabular}{lll}
\hline Pain location & Percentage & Absolute value \\
\hline N/a & $11,5 \%$ & 13 \\
Hipogatrium & $0,9 \%$ & 1 \\
Mesogastrium & $12,4 \%$ & 14 \\
Epigastrium & $75,2 \%$ & 85 \\
\hline
\end{tabular}

Most patients reported not waking up at night due to the complaint. Regarding the alarm signs, when observed $(40 \%)$, the most striking fact was weight loss, in about $14 \%$ of patients (Table 4).

Table 4 Prevalence of patients with alarms signs to do endoscopy

\begin{tabular}{lll}
\hline Alarm signs & Percentage & Absolute value \\
\hline Family history of cancer & $4,3 \%$ & 5 \\
Anemia & $3,5 \%$ & 4 \\
Persistent vomiting & $4,3 \%$ & 5 \\
Bleeding & $4,3 \%$ & 5 \\
Weight loss & $13,9 \%$ & 16 \\
Progressive dysphagia & $5,1 \%$ & 6 \\
Not applicable & $60 \%$ & 71 \\
\hline
\end{tabular}

As for the use of drugs for pain relief, $60 \%$ of patients said they used it. Of these, the most used is proton pump inhibitor - omeprazole. In addition, in the last 3 months, frequent use of this drug was observed, as well as non-hormonal anti-inflammatory drugs (Tables 5\&6).

Table 5 Prevalence of patients using pain medication because of the dyspepsia

\begin{tabular}{lll}
\hline Pain medication & $\begin{array}{l}\text { Percentage } \\
(\mathbf{n}=1 \text { I } \mathbf{0})\end{array}$ & Absolute value \\
\hline Omeprazole & $42,72 \%$ & 47 \\
Buscopan & $4,54 \%$ & 5 \\
Analgesic & $1,81 \%$ & 2 \\
Other & $9 \%$ & 10 \\
Do not know to refer & $41,81 \%$ & 46 \\
\hline
\end{tabular}


Table 6 Prevalence of patients using medicines in the last 3months

\begin{tabular}{lll}
\hline Medicines in the last 3months & Percentage & $\begin{array}{l}\text { Absolute } \\
\text { value }\end{array}$ \\
\hline None & $16,8 \%$ & 24 \\
Nasaid & $24,5 \%$ & 35 \\
Ppi (proton pump inhibitor) & $42 \%$ & 60 \\
H2 inhibitors & $6,3 \%$ & 6 \\
Antibiotics & $2,8 \%$ & 4 \\
Others & $7,7 \%$ & 10 \\
\hline
\end{tabular}

As for habits, he was asked about smoking and drinking. Approximately $56 \%$ of patients have never smoked, and about $14 \%$ are smokers. Of these, most smoke up to a pack of cigarettes a day (Table 7).

Table 7 Prevalence of smokers during the study and how many cigarettes/day

\begin{tabular}{|c|c|c|c|}
\hline Smoking & \multicolumn{2}{|c|}{ Percentage } & Absolute value \\
\hline Smoker & \multicolumn{2}{|l|}{$13,9 \%$} & 14 \\
\hline Ex-smoker & \multicolumn{2}{|l|}{$25,7 \%$} & 26 \\
\hline Never smoked & \multicolumn{2}{|l|}{$56,4 \%$} & 57 \\
\hline $\mathrm{N} / \mathrm{a}$ & \multicolumn{2}{|l|}{$4 \%$} & 2 \\
\hline \multicolumn{2}{|c|}{ Cigarettes/day } & $\begin{array}{l}\text { Percentage } \\
(n=102)\end{array}$ & $\begin{array}{l}\text { Absolute } \\
\text { value }\end{array}$ \\
\hline \multicolumn{2}{|l|}{ Never smoked } & $85,2 \%$ & 87 \\
\hline \multicolumn{2}{|c|}{ I stack/day or less } & $11,76 \%$ & 12 \\
\hline \multicolumn{2}{|c|}{ More than I stack/day } & $2,9 \%$ & 3 \\
\hline
\end{tabular}

Almost half of the sample reports never having used alcohol, approximately $30 \%$ use it moderately and about $7 \%$ are considered alcoholics. Of those who drink, the most consumed is fermented. Weekends are the days that individuals report the greatest consumption (Table 8).

Table 8 Prevalence of alcohol consumption, the type of drink associated and the intensity according to days of the week

\begin{tabular}{lcl}
\hline Alcohol consumption & Percentage & Absolute value \\
\hline Never drink & $47,05 \%$ & 48 \\
Moderate consumption & $31,3 \%$ & 32 \\
Drinker & $6,86 \%$ & 7 \\
Ex-drinker & $14,7 \%$ & 15 \\
\hline & & \\
\hline Drinking type & $\begin{array}{l}\text { Percentage } \\
(\mathbf{n}=105)\end{array}$ & Absolute \\
& value \\
\hline Do not drink (0) & $61,9 \%$ & 65 \\
Fermented (I) & $30,47 \%$ & 32 \\
Distilled (2) & $7,6 \%$ & 8 \\
Others (3) & 0 & 0 \\
\hline
\end{tabular}

\begin{tabular}{lll}
\hline Day the person drink & Percentage & Absolute value \\
\hline Days of the week (2) & $2,9 \%$ & 3 \\
Weekend(I) & $32,4 \%$ & 33 \\
Do not drink (0) & $64,7 \%$ & 65
\end{tabular}

Finally, in relation to the results of the endoscopy, a negative search for H. Pylori was observed in $41.2 \%$ of the patients, and the most common findings were Gastritis, Duodenitis, Mucous Enantema and normal examination (93.14\%) (Tables 9,10).

Table 9 Outcomes of endoscopy

\begin{tabular}{lll}
\hline Results of endoscopy & $\begin{array}{l}\text { Percentage } \\
(\mathbf{n}=\mathbf{I} \text { l })\end{array}$ & $\begin{array}{l}\text { Absolute } \\
\text { value }\end{array}$ \\
\hline GASTRITIS (I) & $86,36 \%$ & 95 \\
GERD gastroesophageal reflux (2) & $2,72 \%$ & 3 \\
ULCER (3) & $4,54 \%$ & 5 \\
CANCER (4) & 0 & 0 \\
OTHERS (5) & $6,36 \%$ & 7
\end{tabular}

Table 10 Prevalence of patients who tested positive for Helicobacter pylori

\begin{tabular}{|c|c|c|}
\hline & Percentage & Absolute value \\
\hline Positive & $25,5 \%$ & 26 \\
\hline Negative & $4 I, 2 \%$ & 38 \\
\hline $\mathrm{N} / \mathrm{a}$ & $33,3 \%$ & 32 \\
\hline
\end{tabular}

\section{Discussion}

The most important finding in this little, single arm and one center study is that the dyspepsia was misdiagnosed and the endoscopy were almost normal, showing that they were not well addressed. As the patients comes from other medical center, we think that is very important elucidate the correct clinical diagnosis of dyspepsia, and the correct indication for endoscopy to our medical doctors. We believe that update the medical education is very important and we need more efforts in that.

H.pylori: As a country with high prevalence of H.pylori, it is associated with the presence of peptic ulcers in order to worsen the bleeding pattern ${ }^{30,31}$ and may be correlated with the genesis of functional dyspepsia. In addition, studies indicate that there is still no consolidated relationship between H.pylori research and autoimmune gastritis, in addition to a negative association between this agent and GERD. However, there are still many controversies regarding the bacterium and dyspeptic symptoms. ${ }^{32}$ This association places the present study in a relationship that is in agreement with the literature, since most results of upper gastrointestinal endoscopy in patients indicated the presence of gastritis $(86.36 \%)$, followed by ulcers $(4.54 \%)$ and GERD $(2.72 \%)$. Since the literature denies the obligatory relationship between the presence of $H$. pylori in endoscopies and the development of gastritis and GERD, a factor that may explain the low prevalence of H.pylori in the endoscopies studied here (41.2\%) is fact that most of the investigated patients had these two pathologies.

Alcohol consumption: Regarding alcohol consumption, there is a contradictory association between alcoholism and dyspeptic 
syndrome. In a 2016 randomized cohort study, 184 subjects were followed for 4 months and it was observed that functional dyspepsia was present in $7.6 \%$ and GERD in $31 \%$ of participants, concluding that the consumption of alcoholic beverages, at least weekly. , was involved in the development of these two outcomes. ${ }^{33}$ However, the present study, evidencing a low association of dyspeptic symptoms with alcohol consumption in the patients analyzed, obtained a result similar to a cross-sectional study carried out among pre- clinical medicine students at Gulf Medical University in Ajman, United Arab Emirates in 2016, which also indicated a non-significant association with alcohol use in dyspepsia when analyzing 176 students with dyspeptic complaints and consumption of this substance. ${ }^{34}$ In a third study analyzed, carried out with 128 fast food workers in a shopping mall in Peru, alcohol consumption was also seen as an aggravation of functional dyspepsia in individuals who used it regularly. ${ }^{35}$

Smoking: In relation to smoking, the same cross-sectional study conducted with medical students at Gulf Medical University, in Ajman, showed a significant relationship between dyspepsia and smoking. ${ }^{34}$ In addition, narghile's consumption was also important in the genesis of dyspeptic syndrome. ${ }^{36-38}$ However, while the literature confirms the existence of a significant relationship between functional dyspepsia and smoking, the study presented here most of the interviewed patients reported never smoking, about $56.4 \%$, making it difficult to analyze this relationship in the studied environment.

Medications: The most part of our patients took pain relief medications, among them the majority of proton pump inhibitors. In the last 3 months, most of the patients submitted to the study presented here used PPI ( $42 \%)$, followed by NSAIDs ( $24.5 \%)$, with a total of $60 \%$ of patients using some pain relief medication. Among them, 35.29\% reported improvement in pain with the use of the medication. The report of symptom improvement with its use is supported by studies that show a large portion of patients with painful symptoms proving improvement of the condition with its use. In relation to other drugs, such as prokinetics, their efficiency still has controversial evidence in the literature, since, among the studies analyzed, one conducted in Germany in 2019 with family doctors showed that these drugs are one of the most used for such symptoms, being Phyto therapeutic in $88.2 \%$ of the time, PPI in $73.6 \%$ and prokinetics in $61.5 \%$. While a bibliographic research published in 2019 concluded that acid suppressive therapy was able to reduce dyspeptic symptoms in 30 $-70 \%$ of patients, with greater benefit in epigastric pain and greater efficacy than proton pump inhibitors compared to H2-antagonists, also showing that prokinetic agents have variable efficiency, and therefore cannot be characterized as a reference for use. ${ }^{39}$

Alarm signs: As for the alarm signs reported by the patients studied here, the most striking symptom was weight loss, around $13.9 \%$ of them, followed by progressive dysphagia in $5.1 \%$, while persistent vomiting, bleeding and a family history of cancer were left with $4.3 \%$ of cases. The reported alarm signs are in accordance with the data also present in a retrospective study, carried out in Nigeria between August 2017 and July 2018, which analyzed 159 endoscopies. ${ }^{40}$ It was seen that $28.6 \%$ of the patients had unexplained weight loss and the most common complaint was dyspepsia of recent onset. Upper gastrointestinal bleeding, persistent vomiting and odynophagia were specific for significant endoscopic findings. ${ }^{41}$ Both the researched studies and the one carried out here, showed that weight loss is the most prevalent alarm signal among patients who undergo upper digestive endoscopies.

Symptoms: The epigastric pain reported by patients undergoing endoscopy, the research carried out had results supported by analyzes already performed worldwide, since when we compared a study addressing North American, Canadian and English patients in 2018 with most articles on dyspepsia, we see that the conclusion reached is similar to that of this study. The main characteristic of pain is having an epigastric location, followed mainly by a feeling of fullness. Most of the patients in this study reported that pain was predominantly in the epigastric region (26.7\%), with no link to bowel habits. Among other reported complaints were gastric burning, bloating, bundling and eructation. These characteristics are in agreement, then, with what most of the articles related to dyspepsia point out, which confirm that most dyspeptic symptoms include epigastric pain, feelings of pressure and fullness, nausea and early subjective satiety. In addition, our study was in accordance with the main characteristics reported in the United States, Canada and the United Kingdom in a study with 6300 adults in the year 2018, which showed that the main symptoms were postprandial discomfort (61\%), $18 \%$ of epigastric pain syndrome and $21 \%$ of the overlap of the two syndromes. ${ }^{43}$

Food intake: Our research identified that the majority of patients had complaints of pain related to food (59\%). Some foods are studied as triggers for dyspeptic complaints. It has been seen that wheat and dietary fats can play key roles in the generation of functional dyspepsia. ${ }^{44}$ In addition, the research carried out in 2016 with 184 individuals seen in a family doctor's office showed that the use of canned food in patients of older age or "fast food" intake was also related to a worse prognosis $(\mathrm{p}<0.002),{ }^{33}$ while, in addition, a crosssectional analytical study carried out in 2018 with 1241 students from 4 medical schools in Latin America, showed that the intake of caffeine was clearly related to the worsening of dyspeptic symptoms. ${ }^{45,46}$

Psychologic aspects: In relation to other symptoms, the presence of depression is associated with the worsening of dyspeptic symptoms, as shown in the same study mentioned above conducted with medical students in 4 schools in Latin America, which also states that the difficulty to sleep is related to the worsening dyspepsia. This is also in line with the study carried out with fast food workers in a shopping center in Peru, in which those who had more difficulty falling asleep or suffered nighttime awakenings had a higher frequency of functional dyspepsia $(p<0.045)^{35}$. In our study, only $21 \%$ of patients had nighttime awakening, which differs from the prevalence of this symptom in patients from the other studies analyzed.

The management of uninvestigated dyspepsia in the absence of alarm features represents a classic medical decision making problem because several strategies exist. These strategies include prompt endoscopy for all patients; test for Helicobacter pylori and perform endoscopy in those who test positive ("test and scope"); test for $H$ pylori and eradication treatment in those who test positive ("test and treat"); empirical acid suppression for all patients; or symptom based management according to guideline recommendations or the physician's usual practice.

The limitations for carrying out this research were the small population sample submitted to the questionnaire (102 people) and the source of a single service, the Gastroenterology Outpatient Clinic and the Digestive Endoscopy Service Faculdade de Medicina ABC in Santo André - SP.

\section{Conclusion}

The study showed that an important portion of the professionals who request upper digestive endoscopy (UDE) from their patients have flawed concepts in relation to the dyspepsia and management of it. This can be noted when observing that the vast majority of patients 
studied presented a condition of heartburn as the main complaint, and the painful complaint had a higher prevalence of score five in the level of pain, among the interviewees. In addition, the characteristics of pain in patients undergoing the examination, both in our research and in the literature, identified dyspeptic conditions that do not necessarily require an UDE, since their diagnosis and treatment are clinical. In addition to the fact that the vast majority of complaints did not justify the request for upper endoscopy for all patients who underwent it, the findings of the exams did not add relevant information to the diagnosis since the expressive majority evidenced gastritis or GERD, corroborating for the hypothesis that professionals need to be adequately oriented as to the correct use of endoscopy as a diagnostic and therapeutic instrument. This need for clarification by health professionals is an extremely relevant conclusion, since the Brazilian health system is increasingly overloaded, so that many unnecessary procedures at that time end up saturating the centers and delaying the performance in patients who really depend on the exam at that time.

\section{Acknowledgments}

None.

\section{Conflicts of interest}

Authors declare that there are no conflicts of interest.

\section{Funding}

None.

\section{References}

1. Tack J. Dyspepsia. In: Feldman M, Friedman Land Brand L, editors Gastrointestinal and Liver Disease. $9^{\text {th }}$ ed. Philadelphia, USA: Saunders Elsevier; 2010. p. 183-185.

2. Vakil N. Peptic Ulcer disease. In: Feldman M, Friedman Brand L, editors. Gastrointestinal and Liver Disease. $9^{\text {th }}$ ed. Philadelphia, USA:Saunders Elsevier; 2010. p. 861-868

3. Mincis M. Differential diagnosis of Jaundice. In: Mincis M, editor. Gastroenterology and Hepatology-diagnosis and treatment. São Paulo: Casa Leitura Médica; 2008. p. 741-751.

4. Silva FM. Dispepsia. In: Benseñor IM, Tiberius IFC, Bernik MMS, Silva, FM, Dórea EL, Lotufo P, editors. Ambulatory medicine. $1^{\text {st }}$ ed. São Paulo: Sarvier; 2006. p. 561-581.

5. Troncon LEA. Functional dyspepsia: review of current concepts. Gastroenterol Endosc Dig. 2001;20(3):97-106.

6. Passos M CF. Dispepsia Funcional. In: Prado FC, Ramos JA, Valle JR, editors. Therapeutic update. $26^{\text {th }}$ ed. São Paulo, Brazil Medical Arts Inc; 2018. p. 1046-1049.

7. Camacho-Lobato 1. Diagnostic Criteria. In:Prado FC, Ramos JA, Valle JR, editor. Therapeutic update. $26^{\text {th }}$ ed. São Paulo, Brazil: Artes Médicas Ltda; 2018. p. 1050-1054.

8. Mimidis K, Tack J. Pathogenesis of Dyspepsia. Dig Dis. 2008;26(3):194202.

9. Dyspepsia and Helicobacter pylori. In: Hora, JAB, Bertolli E, editors Surgical Clinic Gastroenterology. $1^{\text {st }}$ edn. Sao Paulo, Brazil: Medcel; 2012. p. 53-58.

10. Oustamanolakis P, Tack J. Dyspepsia Organic Versus Functional. J Clin Gastroenterol. 2012;46(3):175-190.

11. Ford AC, Marwaha A, Sood R, et al. Global prevalence of, and risk factors for, uninvestigated dyspepsia: a meta- analysis. Gut. 2014;64(7):1-9.
12. Galvão-Alves J, Rodrigues RHR. Dispepsia/Dyspepsia. J Bras Med. 2014;102(4).

13. Miwa H, Kusano M, Arisawa T, et al. Evidence-based clinical practice guidelines for functional dyspepsia. J Gastroenterol. 2015;50:125-139.

14. Pineda, LF, Rosas MC, Amaya MT, et al. Clinical Practice Guideline for the diagnosis and treatment of Dyspepsia in adults. Rev Col Gastroenterol. 2015;30.

15. Camilleri M. Functional Dyspepsia and Gastroparesis. Dig Dis. 2016;34(5):491-499.

16. Tack J. Dyspepsia. In: Feldman M, Friedman LS, Brandt LJ. Gastrointestinal and Liver Disease. 10. Philadelphia, USA: Saunders; 2016. p 194-206e4.

17. Sánchez RC, Escudero OG, Solares MZ, et al. Mexican consensus on dyspepsia. Revista de Gastroenterología de México. 2017;82(4):309327.

18. Talley NJ, Vakil N. Guidelines for the Management of Dyspepsia. Am J Gastroenterol. 2005;100(10):2324-2337.

19. Koduru P, Irani M, Quigley EMM. Definition, Pathogenesis, and Management of That Cursed Dyspepsia. Clin Gastroenterol Hepatol. 2018;16(4):467-479.

20. Madisch A, Andresen V, Enck P, et al. The diagnosis and treatment of functional dyspepsia. Dtsch Arztebl Int. 2018;115:222-232.

21. Silva FM. Dyspepsia: Characterization and Approach. Rev Med (São Paulo). 2008;87(4):213-223.

22. de Oliveira SS, da Silva dos Santos I, da Silva JF, et al. Prevalence of dyspepsia and associated sociodemographic factors. Rev Saude Publica. 2006;40(3):420-427.

23. Shaib Y, El-Serag HB. The prevalence and risk factors of functional dyspepsia in a multiethnic population in the United States. Am J Gastroenterol. 2004;99(11):2210-2216.

24. Almeida, Alessandra Maciel. Prevalence of dyspeptic symptoms and heartburn of adults in Belo Horizonte, Brazil. Arq Gastroenterol. 2017;54(1):47-50.

25. Moayyedi PM, Lacy BE, Andrews CN, et al. ACG and CAG Clinical Guideline: Management of Dyspepsia. Am J Gastroenterol. 2017;112(7):988-1013.

26. Eisen GM, Dominitz CJA, Faigel DO, et al. The role of endoscopy in dyspepsia. Gastrointest Endosc. 2001;54(6):815-817.

27. Salihefendic N, Zildzic M, Cabric E. A New Approach to the Management of Uninvestigated Dyspepsia in Primary Care. Med Arch. 2015;69(2):133-134.

28. Loyd RA, Mcclellan DA. Update on the Evaluation and Management of Functional Dyspepsia. Indian Journal of Clinical Practice. 2013;24:110-114.

29. Correa B, Calazans G, Leite G, et al. Dyspepsia and Endoscopy:For whom and when? - Profile of Endoscopic Findings in 750 Patients. Gastroenterol Hepatol Open Access. 2016;4(5):00117.

30. Sjomina O, Heluwaert F, Moussata D, et al. Helicobacter pylori infection and nonmalignant diseases. Helicobacter. 2017;22 Suppl 1:10.1111/ hel. 12408

31. Venerito M, Vasapolli R, Rokkas T, et al. Helicobacter pylori and Gastrointestinal Malignancies. Helicobacter. 2015;20 Suppl 1:36-39.

32. Coelho LGV, Zaterka S. II Consenso Brasileiro sobre Helicobacter pylori. Arq Gastroenterol. 2005;42(2):128-132.

33. Chirila I, Morariu ID, Barboi OB, et al. The role of diet in the overlap between gastroesophageal reflux disease and functional dyspepsia. Turk J Gastroenterol. 2016;27(1):73-80. 
34. Jaber N, Oudah M, Kowatli A, et al. Dietary and Lifestyle Factors Associated with Dyspepsia among Pre-clinical Medical Students in Ajman, United Arab Emirates. Cent Asian J Glob Health. 2016;5(1):192.

35. Vasquez JR, Mejia CR. Factors associated with functional dyspepsia among fast food workers at a shopping center in Huancayo, Peru. Rev Col Gastroenterol. 2018;33(4).

36. Carvalho CA, Fonseca PCA, Nobre LN, et al. Factors associated with dietary patterns in the second half of life. Science \& Collective Health. 2020;25(2):449-459.

37. Braig S, Berger S, Rothenbacher D, et al. Time trends in dyspepsia and association with $\mathrm{H}$. pylori and work-related stress-An observational study in white collar employees in 1996 and 2015. PLoS One. 2018;13(6):e0199533.

38. Al Saadi T, Idris A, Turk T, et al. Epidemiology and risk factors of uninvestigated dyspepsia, irritable bowel syndrome, and gastroesophageal reflux disease among students of Damascus University, Syria. J Epidemiol Glob Health. 2016;6(4):285-293.

39. Masuy I, Van Oudenhove L, Tack J. Review article: treatment options for functional dyspepsia. Aliment Pharmacol Ther. 2019;49(9):1134-1172.

40. Labenz C, Madisch A, Labenz J. Functional dyspepsia in primary care: therapeutic variety or helplessness? MMW Fortschr Med. 2019;161(Suppl 4):15-19.
41. Odeghe EA, Adeniyi OF, Oyeleke GK, et al. Use of alarm features in predicting significant endoscopic findings in Nigerian patients with dyspepsia. Pan Afr Med J. 2019;34:66.

42. Madisch A, Andresen V, Enck P, et al. The Diagnosis and Treatment of Functional Dyspepsia. Dtsch Arztebl Int. 2018;115(13):222-232.

43. Aziz I, Palsson OS, Törnblom H, et al. Epidemiology, clinical characteristics, and associations for symptom-based Rome IV functional dyspepsia in adults in the USA, Canada, and the UK: a cross-sectional population-based study. Lancet Gastroenterol Hepatol. 2018;3(4):252262

44. Troncon LEA. New Drugs in the Treatment of Functional Dyspepsy. Arq Gastroenterol. 38(3):2017-212.

45. Talledo-Ulfe L, Buitrago OD, Filorio Y, et al. Factors associated with uninvestigated dyspepsia in students at 4 Latin American schools of medicine:A multicenter study. Rev Gastroenterol Mex. 2018;83(3):215222

46. Eusebi LH, Black CJ, Howden CW, et al. Effectiveness of management strategies for uninvestigated dyspepsia: systematic review and network meta-analysis. BMJ. 2019;367:16483. 